\title{
LETTER TO THE EDITOR \\ Pomegranate Juice Intake and Cardiovascular Health
}

\author{
Venetia Notara and Demosthenes B. Panagiotakos* \\ Department of Nutrition and Dietetics, Harokopio University, Athens, Greece
}

The public health burden of cardiovascular diseases (CVDs) is substantial. According to the World Health Organization report "The Global Burden of Disease" 2013 Update, heart diseases are expected to take the second place in the rank order of disease and injury burden by the year 2030 [1]. More than $50 \%$ reduction of CVD mortality is attributable to favourable changes in risk factors, while $43 \%$ to new medical and surgical treatment [2,3]. Extended research data has indicated that diet is one of the modifiable risk factors that has been substantially related to CVD prevention, through several serum antioxidant and antithrombotic mechanisms. Emphasis has been given to the daily consumption of fruits and vegetables due to the high source, among others, of phenolic acids and flavonoids that are known for their antioxidant properties [4]. In the most recent years, laboratory and clinical studies have examined the health benefits of pomegranate juice consumption, which have demonstrated its protective effect against the progression of atherosclerosis [5]. Pomegranate fruit has very high levels of antioxidants- mainly polyphenols- as well as tannins and anthocyanins, which seem to improve vascular function and modulation of inflammation. In a recent study conducted in a sample of people with hypertension, it has been observed that pomegranate juice can significantly lower blood pressure even in a 2-week intake of fresh juice [6]. Polyphenolic flavonoids are powerful antioxidants which can inhibit the harmful oxidation effect of low-density LDL and consequently restrain atherosclerosis development [7]. Pomegranate seed oil consumption seems to be associated with an improvement in insulin sensitivity, posing an additional protective effect in the development of type 2 diabetes [8]. However, in the same study the CVD - related risk did not change, while other studies did not show a decrease in the type 2 diabetes risk or a reduction in the lipid peroxidation among healthy controls, too [5,9]. It should also be mentioned, that pomegranate seed oil does not have polyhpenols.

*Address correspondence to this author at the 70 Eleftheriou Venizelou str, Harokopio University in Athens, Greece; Tel: 00302109549332 ;

E-mail:dbpanag@hua.gr
Despite the fact that dietary flavonoids seem to have a potential effect on the reduction of CVD risk, the question of whether isolated polyphenols are the responsible compounds for vascular health still remains unanswered. Long-term clinical studies exploring the bioactive compounds of various types of fruits are required to determine the potential synergistic effects of polyphenols and the dose-response relationships [10]. Additionally, the impact of pomegranate polyphenol extracts among healthy and high CVD risk subjects needs further investigation.

\section{CONFLICT OF INTEREST}

The authors confirm that this article content has no conflicts of interest.

\section{ACKNOWLEDGEMENTS}

Declared none.

\section{REFERENCES}

[1] WHO Fact sheet No 317, (Updated March 2013). Available at: http://www.who.int/mediacentre/factsheets/fs317/en/. Last accessed August 29, 2013.

[2] Wijeysundera HC, Machado M, Farahati F, et al. Association of temporal trends in risk factors and treatment uptake with coronary heart disease mortality, 1994-2005. JAMA 2010; 303(18): 1841-7.

[3] Bandosz P, O'Flaherty M, Drygas W, et al. Decline in mortality from coronary heart disease in Poland after socioeconomic transformation: modelling study. BMJ 2012; 344: d8136.

[4] Panagiotakos DB, Pitsavos C, Arvaniti F, Stefanadis C. Adherence to the Mediterranean food pattern predicts the prevalence of hypertension, hypercholesterolemia, diabetes and obesity, among healthy adults; the accuracy of the MedDietScore. Prev Med 2007; 44(4): 335-40.

[5] Aviram M, Rosenblat M, Gaitini D, et al. Pomegranate juice consumption for 3 years by patients with carotid artery stenosis reduces common carotid intima-media thickness, blood pressure and LDL oxidation. Clin Nutr J 2004; 23(3): 423-33.

[6] Asgary S, Sahebkar A, Afshani MR, Keshvari M, Haghjooyjavanmard S, Rafieian-Kopaei M. Clinical evaluation of blood pressure lowering, endothelial function improving, hypolipidemic and anti-inflammatory effects of pomegranate juice in hypertensive subjects. Phytother Res 2013 [Epub ahead of print]

[7] Aviram M, Rosenblat M. Pomegranate Protection against Cardiovascular Diseases. Evid Based Complement Alternat Med 2012; 382763 . 
[8] McFarlin BK, Strohacker KA, Kueht ML. Pomegranate seed oil consumption during a period of high-fat feeding reduces weight gain and reduces type 2 diabetes risk in CD-1 mice. Br J Nutr 2009; 102(1): 54-9.

[9] Basu A, Newman ED, Bryant AL, Lyons TJ, Betts NM. Pomegranate polyphenols lower lipid peroxidation in adults with type 2diabetes but have no effects in healthy volunteers: a pilot study. J Nutr Metab 2013; 708381. Epub 2013 Jul 10.

[10] Chong MF, Macdonald R, Lovegrove JA.Fruit polyphenols and CVD risk: a review of human intervention studies. $\mathrm{Br} \mathrm{J}$ Nutr 2010; 104 Suppl 3: S28-39.

(C) Notara and Panagiotakos; Licensee Bentham Open.

This is an open access article licensed under the terms of the Creative Commons Attribution Non-Commercial License (http://creativecommons.org/ licenses/by-nc/3.0/) which permits unrestricted, non-commercial use, distribution and reproduction in any medium, provided the work is properly cited. 